\title{
Significant impact from blue mussel Mytilus galloprovincialis biofouling on aquaculture production of green-lipped mussels in New Zealand
}

\author{
Barrie M. Forrest ${ }^{*}$, Javier Atalah \\ Cawthron Institute, Nelson 7010, New Zealand
}

\begin{abstract}
Biofouling by blue mussels Mytilus galloprovincialis is a persistent regional-scale problem for green-lipped mussel Perna canaliculus aquaculture in New Zealand's Marlborough Sounds. M. galloprovincialis impacts on $P$. canaliculus crop production were assessed using a $4 \mathrm{yr}$ dataset representing 243 different mussel farms. Together with information on other production impacts from M. galloprovincialis and associated management costs, we estimated the regionalscale economic consequences of mussel biofouling. Mean ( $\pm 95 \%$ CI) M. galloprovincialis cover on mussel crops across the study region was $9.17 \pm 0.5 \%$, with the worst-affected crops experiencing up to $99 \%$ cover. $P$. canaliculus yield per crop depended on the spat type used for grow-out, and declined with increasing grow-out duration at a rate of ca. $1 \mathrm{~kg} \mathrm{yr}^{-1} \mathrm{~m}^{-1}$ of cultivation line, due to M. galloprovincialis biofouling and a range of other possible factors. For M. galloprovincialis alone, regression models predicted a decrease in annualised $P$. canaliculus yield of ca. 5 to $10 \%$ at mean $M$. galloprovincialis cover, depending on spat type. This decline represented an average loss of regional economic value of $\$ 11.4$ million $\mathrm{yr}^{-1}$ USD (range $\$ 8.0$ to 15.4 million). When impacts on seed-stock supply and costs incurred for mitigation were also accounted for, the economic loss from $M$. galloprovincialis biofouling was estimated at $\$ 16.4$ million $\mathrm{yr}^{-1}$, which represents $10 \%$ of the regional value of the mussel industry. The discussion highlights a dearth of comparable quantitative studies of the economic consequences of biofouling. There is a need for consistent approaches to reporting such consequences to enable comparisons among different locations, biofouling species and types of aquaculture.
\end{abstract}

KEY WORDS: Perna canaliculus - Bivalve aquaculture - Over-settlement - Biofouling impact · Mitigation cost $\cdot$ Marlborough Sounds

\section{INTRODUCTION}

Marine biofouling is a significant threat to sustainable aquaculture production, with a wide range of impacts reported both for specific species and for biofouling assemblages generally (Hancock 1954, Elston 1997, Lane \& Willemsen 2004, Daigle \& Herbinger 2009, Carver et al. 2010, Lacoste \& GaertnerMazouni 2015). Shellfish production using off-bottom or floating subtidal systems is particularly vulnerable to adverse impacts (Adams et al. 2011), as such sys-

\footnotetext{
*Corresponding author: barrie.forrest@cawthron.org.nz
}

tems provide habitats on which sessile biofouling organisms can proliferate (Glasby \& Connell 2001, O'Beirn et al. 2004, Woods et al. 2012). The generic types of impacts from biofouling on shellfish aquaculture are well-described and occur at all production stages, including the supply of spat (juvenile shellfish), crop grow-out, harvesting, processing and product marketing (Padilla et al. 2011, Fitridge et al. 2012, Forrest et al. 2014). From these studies, it is evident that biofouling can impact the quality, yield and value of the shellfish crop (e.g. via space and food

(C) The authors 2017. Open Access under Creative Commons by Attribution Licence. Use, distribution and reproduction are unrestricted. Authors and original publication must be credited. 
competition, predation, shell erosion), impact infrastructure (e.g. through excessive weight and drag), and impede industry processes such as harvesting (e.g. via physical interference).

The attention of many shellfish aquaculture biofouling studies has been on the effects of non-indigenous tunicates (Ramsay et al. 2008, Rocha et al. 2009, Fletcher et al. 2013). However, recent reviews and syntheses highlight that problematic species occur across many different phyla, and reveal that indigenous organisms from local aquaculture environments can be of equal importance as or greater importance than non-indigenous species (Padilla et al. 2011, Fitridge et al. 2012, Booth 2014, Forrest et al. 2014). Despite this situation, very few studies provide unambiguous evidence and quantitative data to support claims of adverse effects. A recent review (Forrest et al. 2014) found that the majority of reports of biofouling impacts on shellfish aquaculture were anecdotal, based on small-scale experimental investigations or restricted to specific locations and short time periods (e.g. Fletcher et al. 2013, Sievers et al. 2013).

Challenges in quantifying impacts due to specific species arise for a number of reasons, one being that biofouling management is a routine operational activity of marine aquaculture, making the incremental effects of particular species difficult to disaggregate. Coupled with this constraint is that different species (even similar species) can have differential and sometimes complex effects in relation to different stages of production and among different culture species or cultivation methods. Perhaps the most significant challenge for management decisionmaking is that problem species tend to vary among locations, and very seldom persist at problematic abundances for long durations (Dharmaraj et al. 1987, de Sá et al. 2007, Ramsay et al. 2008, Fragoso \& Icely 2009, de Francesco \& Murray 2010). An exception to this situation occurs in New Zealand's primary mussel growing region of the Marlborough Sounds (Fig. 1), where biofouling by blue mussels Mytilus galloprovincialis (hereafter Mytilus) has had regional-scale impacts on the production of green-lipped mussels Perna canaliculus (hereafter Perna) since the mussel industry began in the 1970s (Jenkins 2011). New Zealand blue mussels are a Southern Hemisphere lineage of the Mediterranean mussel M. galloprovincialis, and part of the $M$. edulis species complex (Gardner et al. 2016).

At early stages of Perna aquaculture, biofouling by Mytilus prevents Perna spat settlement, or oversettlement displaces Perna on spat-catching lines leading to effects on down-stream production. To mitigate this impact, a web-based tool has been developed that identifies optimal times, locations and water depths where spat (or spat-catching gear) can be deployed to avoid high densities of Mytilus (Atalah et al. 2016). Despite progress being made to better secure spat and seed-mussel supply, Perna crops remain vulnerable to biofouling by Mytilus during their period of grow-out from final seeding to harvest (typically 1 to $3 \mathrm{yr}$ ). During this time, the excessive weight of Mytilus can strip Perna from crop lines when they are lifted from the water, and Mytilus must be removed from the harvested crop, usually by size-grading or hand sorting. Furthermore, to support the excess weight on crops and farm structures, additional on-farm flotation may be needed.

Although Mytilus has been problematic for mussel aquaculture for several decades, its prevalence and production impact in the Marlborough Sounds has never been fully quantified and reported. As the

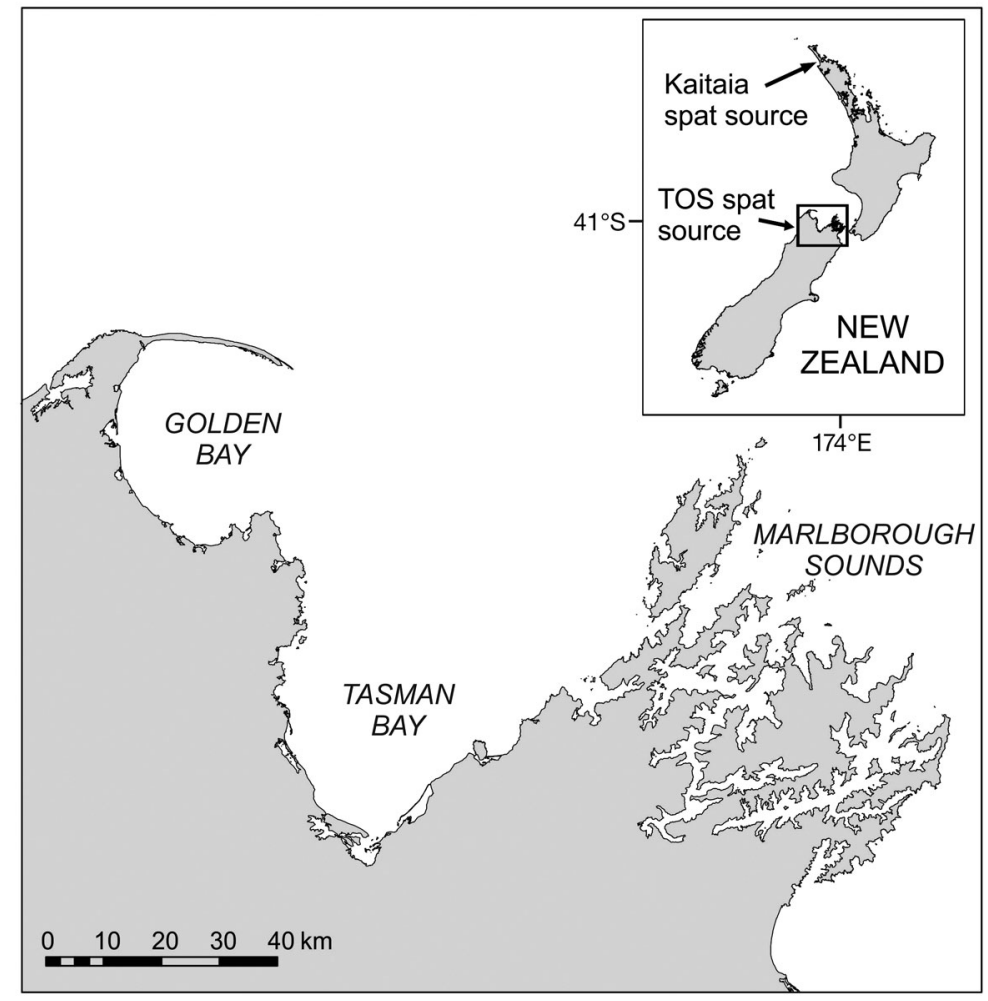

Fig. 1. Map showing Marlborough Sounds region of central New Zealand, and mussel spat supply locations referred to in the text. TOS: top-of-the-South 
Marlborough region produces around $60 \%$ of New Zealand's Perna crop, there is a recognised need by the mussel industry to better quantify the nature and magnitude of the issue. Accordingly, the industry has maintained extensive production records, involving periodic assessment of seed-stock and crops on growout farms, along with visual percentage cover estimates of the extent of biofouling by Mytilus. These farm records can be linked to processing factory data on Perna yield from individual crops. The main objective of this study was to determine the economic consequences of Mytilus biofouling for the regional mussel industry. We focused on assessing the impact of Mytilus on Perna crop yield on grow-out farms. However, we also characterised other recognised sources of impact from Mytilus, including the cost of implementing mitigation measures, in order to provide a whole-of-production-chain estimate of economic consequences at a regional scale.

\section{MATERIALS AND METHODS}

\section{Description of mussel industry and operations}

Mussel farms are widespread among numerous bays and sub-regions of the wider Marlborough Sounds. The majority of farms are 3 to 4 ha in size and typically consist of 10 floating double 'backbone' anchor lines fixed to the seabed at each end. Each double backbone has a single continuous production longline suspended beneath it, to a maximum depth of ca. $15 \mathrm{~m}$ (Jeffs et al. 1999). The industry relies primarily on wild-caught spat, which is grown via 1 or 2 longline production stages to a length of ca. 50 to $60 \mathrm{~mm}$, at which point the 'seed' mussels are stripped and reseeded to 'crop' longlines at a density of ca. $160 \mathrm{~m}^{-1}$. Management measures are typically implemented at this final seeding stage to remove Mytilus and other biofouling (e.g. size-grading). Thereafter, the reseeded Perna remain on crop lines until harvest at ca. $96 \mathrm{~mm}$ length. The final Perna seed used for each crop is often sourced from other farms, depending on supply and demand. An individual farm typically has crop longlines at different stages of growout; hence, some longlines may be close to harvest whereas others may have been recently seeded.

\section{Datasets for Mytilus and Perna}

A dataset containing records of Mytilus biofouling and Perna production variables was obtained from an aquaculture company that owns or manages almost half (48\%) of the mussel farms in the Marlborough Sounds region. These records contained all of the monitoring conducted on crop lines; i.e. the lines on which seed mussels are deployed for final growout. The company's visual assessment of Mytilus percentage cover is made on sections of longline (ca. $2 \mathrm{~m}$ length) that are lifted from the water for inspection. In each section, the company assessor estimates the percentage of primary cover occupied by Mytilus. This type of visual assessment method is recognised as a reliable means of rapidly quantifying percent cover over large areas (Meese \& Tomich 1992). Mytilus galloprovincialis is the only species of Mytilus present in the wider region (Gardner et al. 2016), and its primary cover is readily distinguishable from Perna and the occasional other bivalve species that occur on the crop lines. Typically, $3 \times 2 \mathrm{~m}$ sections of crop are inspected between the surface and the bottom of the longline. Most crops are inspected over multiple occasions leading up to the time of harvest, with a single random line inspected for each crop on each occasion. Although the company's data on the prevalence of Mytilus extended back to 2006, monitoring was inconsistent until 2012. Beginning in 2012, the percentage cover assessment was conducted routinely and consistently by the same 2 personnel at farms throughout the Marlborough Sounds region. As such, the dataset for our analysis covered a $4 \mathrm{yr}$ period from the start of 2012 to the end of 2015.

Following quality assurance checks to exclude data input errors or incomplete fields, the dataset contained 3369 crops, outgrown at 243 different mussel farms spread among 70 different bays throughout the region. As Mytilus prevalence at affected farms tended to increase during the duration of crop growout, the key Mytilus variable for all of our analyses was the $95^{\text {th }}$ percentile of Mytilus cover derived from the multiple inspections ( $\mathrm{n}=1$ to 24 , mean ca. 13) conducted for each crop. The $95^{\text {th }}$ percentile cover was preferred over the maximum value in order to avoid potential outliers. Accordingly, for each of the 3369 individual crops the dataset contained a single Mytilus value (hereafter referred to as 'Mytilus cover') that could be matched to Perna harvest yields derived from factory processing records. Yield was defined as the live-weight of harvested Perna $\left(\mathrm{kg} \mathrm{m}^{-1}\right.$ of crop longline) after post-harvest processing and removal of waste material. The latter included Mytilus, other biofouling and damaged product (e.g. Perna with broken shells).

All analyses described below were conducted using $\mathrm{R}$ software (R Core Team 2014). Initial data explo- 
ration revealed that the type of spat from which the Perna crops are outgrown was an important covariate for explaining variations in Mytilus cover and Perna yield. The industry relies on 2 main spat types: spat naturally attached to beach-cast seaweed in northern New Zealand ('Kaitaia' spat), and spat caught on artificial collectors in northern bays of New Zealand's South Island (Golden Bay, Tasman Bay and the Marlborough Sounds; Fig. 1), which we refer to as top-of-the-South (TOS) spat. Each spat type was well-represented in the dataset, with 47 and $53 \%$ of crops outgrown from Kaitaia and TOS spat, respectively.

\section{Regional prevalence and distribution of Mytilus}

The regional distribution of Mytilus cover for individual farms was visualised using a bubble plot based on the mean cover across multiple crops outgrown at each farm over the 4 yr period. Differences in the regional prevalence of Mytilus in relation to each spat type were assessed using a generalised linear mixed model within the 'gamlss' R package (Stasinopoulos \& Rigby 2014). Mytilus cover divided by 100 was used as the response variable in a model with a zero-inflated beta error distribution and log link function, specified to account for a large proportion of zeros $(27 \%)$. The model included spat type (Kaitaia and TOS) as a fixed effect, and farms (243 farms) nested within bays (70 bays) as a random effect. The model was validated by inspecting the normalised quantile residuals.

\section{Effect of crop grow-out duration, spat type and Mytilus cover on Perna yield}

Perna yield $\left(\mathrm{kg} \mathrm{m}^{-1}\right)$ per crop was initially modelled in relation to 2 key explanatory variables: crop growout duration (months) and spat type (Kaitaia and TOS). The effect on Perna yield was tested using a linear model with spat type as a fixed effect and crop grow-out duration as a continuous covariate. In order to compare yield between the 2 spat types in a standardised way and enable prediction of the impact of Mytilus alone, a second analysis used annualised Perna yield (Perna $\mathrm{kg} \mathrm{m}^{-1} \mathrm{yr}^{-1}$ ) as the response variable. This second analysis involved a generalised least squares regression (GLS) using the R library 'nlme' (Pinheiro et al. 2016). The fixed part of the GLS model specified annual Perna yield as a function of Mytilus cover and spat type. The optimal random part of the model consisted of a constant plus power variance function structure (the 'varConstPower' function in 'nlme') by spat type to account for a strong residual heterogeneity pattern detected in the fitted values. To account for spatial autocorrelation, an exponential structure term (the 'corExp' function in 'nlme') was used in the model to reflect that the annual yield of crops grown within a farm could be more similar to yield at different farms. Models were selected based on Akaike's information criterion (AIC) and validated by inspecting residuals (Zuur et al. 2010, Zuur \& Ieno 2016).

\section{Calculation of economic consequences of Mytilus biofouling}

We assessed the economic implications of the reduced annual Perna yield attributable to Mytilus biofouling using the linear model intercept and slope estimates predicted by the GLS regression. The model intercept estimates were taken to reflect the 'baseline' annual Perna yields for each spat type in the absence of Mytilus. We considered it reasonable to estimate the regional-scale economic impact of Mytilus on the basis that our analysis incorporated $48 \%$ of the mussel farms in the Marlborough Sounds, and represented all growing areas in the region. The regional-scale impact was calculated for crops outgrown from each spat type, using the percentage reductions in annual Perna yield (from the baseline) that were estimated to occur at mean Mytilus cover. The corresponding economic loss (for each spat type, and combined) was calculated, given an annual revenue generated by the regional mussel industry of ca. USD \$160 million. This figure comprises reported regional export sales of USD \$146 million (NZIER 2015), with a conservative assumption based on industry statistics that the domestic market provides an additional revenue of ca. $10 \%$ (ca. USD \$14 to 15 million). The contribution of the 2 spat types to regional revenue was determined according to the proportion of crops outgrown from each.

In addition to the regional assessment of crop impact, it was of interest to understand the other sources of economic loss from Mytilus, in order to provide a whole-of-production-chain estimate. The impact on mussel spat and seed supply was calculated from unpublished industry data for the same 2012-2015 time period. That data showed a 13\% mean percentage cover of Mytilus on spat and seed ropes, based on which it was assumed that there would be an equivalent $13 \%$ loss of spat and 
seed mussels. Additionally, the costs of implementing measures to mitigate the effects of Mytilus across all production stages were estimated by company representatives, based on 6 categories of impact that were identified: (1) the cost to implement a regional programme to monitor Mytilus recruitment patterns; (2) boat and labour costs for farm maintenance activities (e.g. adding extra flotation to lines); (3) boat and labour costs for grading spat, seed and crop to remove $M Y$ tilus; (4) additional boat and labour costs incurred at harvesting; (5) processing factory labour costs for hand-removal of Mytilus; and (6) costs for transport and land-disposal of Mytilus waste generated during factory processing. Cost details within each of these categories are not reported for reasons of confidentiality.

\section{RESULTS}

\section{Regional prevalence of Mytilus}

Across all crops in the mussel farming region, Mytilus cover ranged from 0 to $99 \%$, with an overall mean $( \pm 95 \% \mathrm{CI})$ of $9.17 \pm 0.50 \%$. Mean Mytilus cover on crops outgrown from Kaitaia spat (10.74 \pm $0.77 \%$ ) was significantly greater than for TOS spat $(7.77 \pm 0.64 \%)$ (beta regression $t$-value $=-4.94, \mathrm{p}<0.001)$. At the farm scale, the worst-case Mytilus cover, illustrated by the $95^{\text {th }}$ percentile of farm-scale means, was $24.89 \%$ for crops outgrown from TOS spat, and $32.80 \%$ for Kaitaia. Spatial patterns in farm-scale cover revealed that the worst affected farms were mainly in the inner- to mid-Pelorus Sound sub-region (Fig. 2). However, cover was highly variable among farms, with beta regression results indicating that variability in Mytilus cover among farms within bays $(\mathrm{SD}=0.32$ ) was as high as that among bays ( $\mathrm{SD}=0.29)$.

\section{Perna crop yield and impact of Mytilus}

Perna yield per crop ranged widely from 0.49 to $13.49 \mathrm{~kg} \mathrm{~m}^{-1}$ of culture rope (Fig. 3),

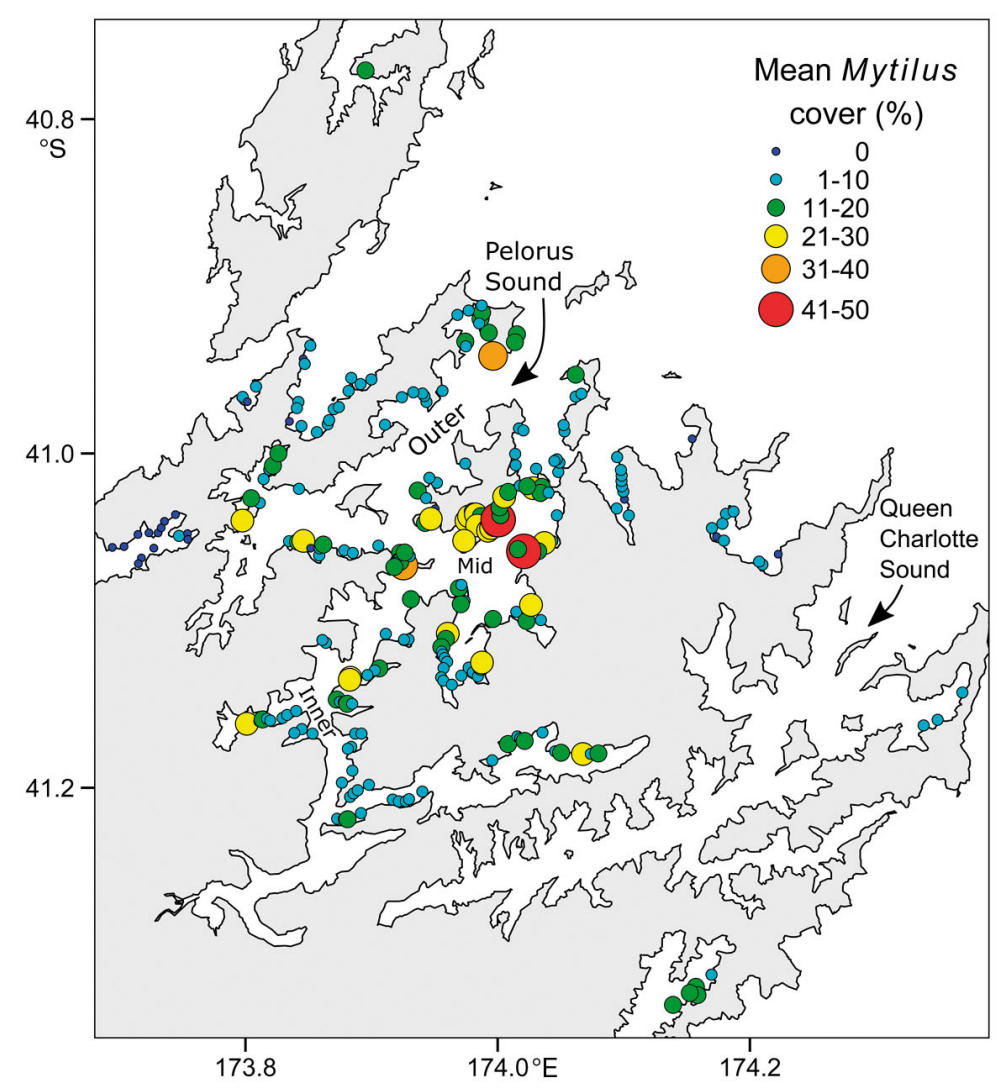

Fig. 2. Regional distribution of Mytilus galloprovincialis cover (\%) in the Marlborough Sounds based on farm-averaged cover across multiple crops harvested from each of 243 mussel farm sites during 2012 to 2015. The main general areas of Pelorus Sound are indicated, including the worst affected locations (mid- and inner-) referred to in the text

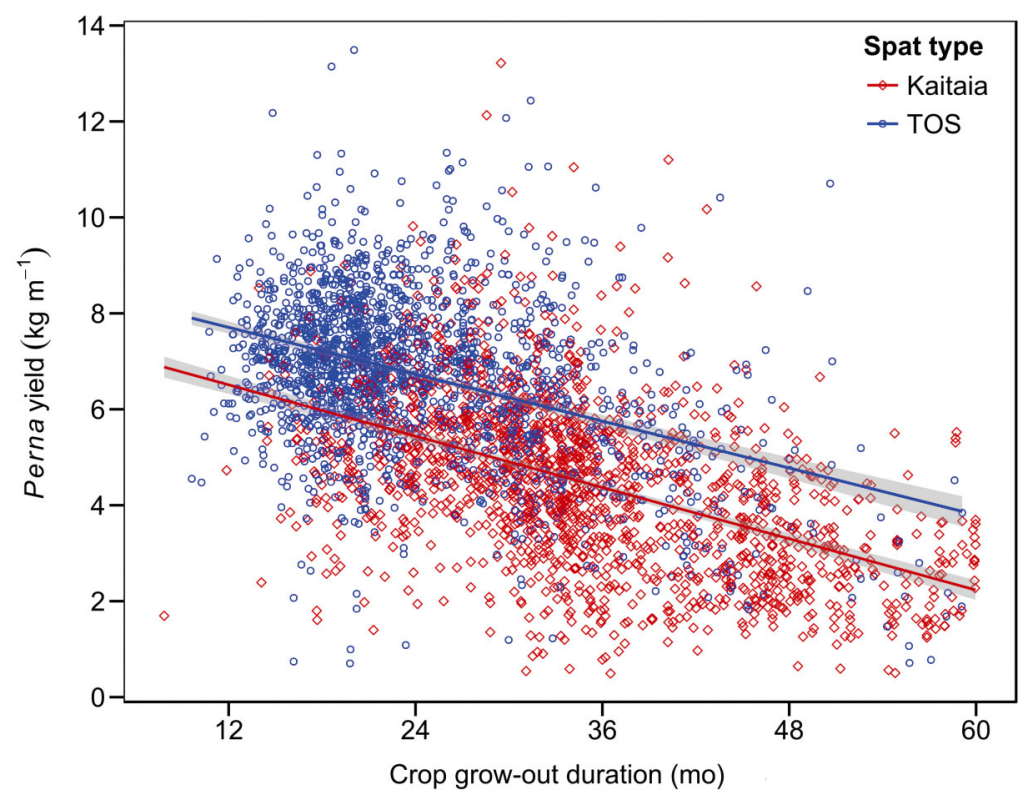

Fig. 3. Perna canaliculus yield per crop in relation to grow-out duration and spat type (Kaitaia and top-of-the-South; TOS). Linear regression lines are bounded with $95 \%$ confidence intervals (grey shading) 
with a mean $( \pm 95 \% \mathrm{CI})$ yield of $5.67 \pm 0.07$ $\mathrm{kg} \mathrm{m}^{-1}$. Yield differed significantly between the 2 spat types $\left(F_{1,3366}=458, \mathrm{p}<\right.$ 0.001; Fig. 3), with TOS spat on average yielding $6.87 \pm 0.08 \mathrm{~kg} \mathrm{~m}^{-1}$ of Perna crop at harvest, compared with $4.51 \pm 0.09 \mathrm{~kg}$ $\mathrm{m}^{-1}$ for Kaitaia spat. Moreover, crops outgrown from TOS spat reached harvest size and condition more quickly, being harvested on average $( \pm 95 \% \mathrm{CI})$ after $2 \mathrm{yr}$ $(24 \pm 0.38 \mathrm{mo})$. By contrast, the required grow-out duration for Kaitaia crops was about $50 \%$ longer at ca. 3 yr ( $35 \pm 0.49 \mathrm{mo})$. Although counter-intuitive, mussel yield among different crops decreased with increasing crop grow-out duration for both spat types. Linear model estimates predicted a mussel yield decline of $0.086 \mathrm{~kg}$ $\mathrm{m}^{-1} \mathrm{mo}^{-1}$, equating to ca. $1 \mathrm{~kg} \mathrm{~m}^{-1} \mathrm{yr}^{-1}$ of grow-out.

When crop grow-out duration was taken into account and annual Perna yield considered, the contrast between spat types was particularly evident (Fig. 4). Based on intercept and slope coefficients from the GLS, the relationship between annual Perna yield and Mytilus cover for each spat type was described by the following models:

Yield $_{\text {Kaitaia }}=2.03-0.0196 \times$ Mytilus

Yield $_{\mathrm{TOS}}=$

$$
(2.03+1.88)-(0.0196-0.0088) \times \text { Mytilus }
$$

In the absence of Mytilus, a baseline Perna yield of $3.91 \mathrm{~kg} \mathrm{~m}^{-1} \mathrm{yr}^{-1}$ was predicted for TOS spat, which is close to twice the $2.03 \mathrm{~kg} \mathrm{~m}^{-1} \mathrm{yr}^{-1}$ estimated for Kaitaia spat (Table 1). However, for both spat types

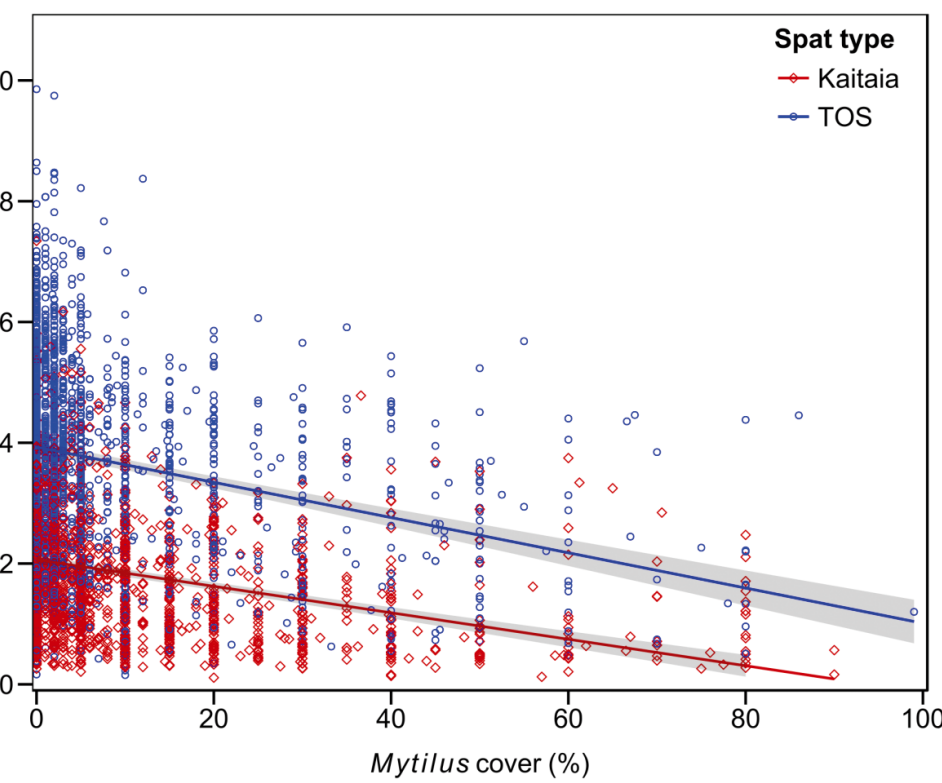

Fig. 4. Annualised yield of Perna canaliculus for crops outgrown from 2 spat types (Kaitaia and top-of-the-South; TOS), in relation to Mytilus galloprovincialis cover. Linear regression lines are bounded with $95 \%$ confidence inter-vals (grey shading) predicted from the generalised least squares regression (GLS) model

annual yield was clearly highly variable irrespective of the presence of Mytilus (Fig. 4). There was a significant decline in annual Perna yield with increasing cover of Mytilus (Fig. 4); the decline being marginally more pronounced for TOS than for Kaitaia spat (Mytilus cover $\times$ spat type, $F_{1,2364}=4.423, \mathrm{p}=0.036$ ). The GLS model predicted that for every $10 \%$ increase in Mytilus cover the annual Perna yield would decrease by $0.284 \mathrm{~kg} \mathrm{~m}^{-1} \mathrm{yr}^{-1}$ in the case of TOS spat, and $0.196 \mathrm{~kg} \mathrm{~m}^{-1} \mathrm{yr}^{-1}$ for Kaitaia. Decreases in regional-scale annual Perna yield at mean Mytilus cover were predicted to be 5.63 and $10.34 \%$ for TOS and Kaitaia spat, respectively. However, the $95 \%$ CI

Table 1. Predicted reductions in the annual yield of green-lipped mussel Perna canaliculus crops in the Marlborough Sounds in relation to Mytilus galloprovincialis biofouling, with associated economic loss at a regional scale. All monetary values are expressed in USD ( $\mathrm{M}=$ millions of dollars), calculated from raw data in NZD using an exchange rate of NZD $\$ 1.00=$ USD \$0.70. Bracketed numbers represent 95\% confidence intervals of estimates. Reductions in baseline yield for each spat type are based on model slope estimates. TOS: top-of-the-South

\begin{tabular}{|lcc|}
\hline Impacts and values & TOS spat & Kaitaia spat \\
\hline Annual value of crops from each spat type (USD) & $109.1 \mathrm{M}$ & $50.9 \mathrm{M}$ \\
Mean regional Mytilus cover $(\%)$ & $7.77(7.13-8.41)$ & $10.74(9.97-11.51)$ \\
Baseline yield in absence of Mytilus $\left(\mathrm{kg} \mathrm{m}^{-1} \mathrm{yr}^{-1}\right)$ & $3.91(3.76-4.07)$ & $2.03(1.97-2.1)$ \\
Reduction (\%) in baseline yield & $5.63(3.67-8.04)$ & $10.34(8.03-13.04)$ \\
Loss of annual value (USD) & $6.2 \mathrm{M}(4.0-8.8 \mathrm{M})$ & $5.3 \mathrm{M}(4.0-6.6 \mathrm{M})$ \\
Annual regional loss due to impact on Perna crop (USD) & $11.4 \mathrm{M}(8.0-15.4 \mathrm{M})$ \\
a The regional-scale economic loss (USD yr ${ }^{-1}$ ) due to the impact on Perna crop is based on an annual regional mussel aqua- \\
culture revenue of USD \$160 million, calculated from reported export sales of USD \$146 million (NZIER 2015) with a \\
conservative 10\% increment to reflect domestic sales
\end{tabular}


values around these means were on the order of $\pm 30 \%$ of the TOS estimate and $\pm 20 \%$ of the Kaitaia estimate (Table 1).

\section{Economic consequences}

The average Perna crop yield declines attributed to Mytilus translated to a regional revenue loss of USD \$11.4 million annually, with the range in 95\% CI values being $\$ 8.0$ to $\$ 15.4$ million (Table 1 ). In addition to impacts on crop production, Table 2 shows the other direct production impacts in terms of estimated losses of spat and seed, as well as the costs of managing Mytilus fouling. Clearly, the crop loss estimate in Table 1 is the most significant component of the economic effect. However, considerable costs are also incurred due to the reduction in supply of spat and seed for grow-out farms, and the increased vessel and labour needed to control Mytilus fouling levels on farm structures (e.g. floats, anchor warps) and product lines (i.e. spat, seed and crop). The total economic loss attributed to Mytilus was calculated to be almost USD \$16.4 million annually (Table 2), which equates to $10 \%$ of annual regional revenue from the mussel industry.

Table 2. Estimated annual regional economic loss due to Mytilus galloprovincialis across all stages of the industry production chain for Perna canaliculus. All monetary values are expressed in USD, calculated from raw data in NZD using an exchange rate of NZD $\$ 1.00=$ USD $\$ 0.70$. See 'Materials and methods' for assumptions)

\begin{tabular}{|lc|}
\hline Cost component & $\begin{array}{c}\text { Annual regional } \\
\text { cost (USD) }\end{array}$ \\
\hline $\begin{array}{l}\text { Cost from direct production impact on } \\
\text { Loss of Perna spat }\end{array}$ \\
$\begin{array}{l}\text { Loss of Perna seed mussels } \\
\text { Loss of Perna crop (mean value from }\end{array}$ & $\$ 190573$ \\
$\quad$ Table 1) & $\$ 14900000$ \\
$\begin{array}{l}\text { Subtotal cost from production impact } \\
\text { on Perna }\end{array}$ & $\$ 12409531$ \\
Cost of managing Mytilus biofouling & \\
Monitoring programme for Mytilus & $\$ 41300$ \\
$\begin{array}{l}\text { Farm maintenance } \\
\text { Seeding and grading (spat, seed }\end{array}$ & $\$ 1239583$ \\
$\quad$ and crop) & $\$ 1750000$ \\
Harvesting & $\$ 320833$ \\
Factory sorting & $\$ 320833$ \\
Factory waste disposal (to landfill) & $\$ 284375$ \\
Subtotal cost of Mytilus management & $\$ 3956925$ \\
Total (sum of the 2 subtotals) annual & $\$ 16366456$ \\
loss for regional industry (USD) & \\
\hline
\end{tabular}

\section{DISCUSSION}

\section{Extent of biofouling by Mytilus}

Biofouling by bivalves is widely reported as a significant problem in shellfish aquaculture globally. Mytilus galloprovincialis, other mytilid species (e.g. M. edulis, $M$. trossulus, Perna viridis), Pacific oysters (Crassostrea gigas), and various shell-boring species (e.g. Hiatella arctica, Lithophaga sp.) are among the main bivalves cited as having significant impacts (Alagarswami \& Chellam 1976, Arakawa 1980, Dharmaraj et al. 1987, Claereboudt et al. 1994, Khalaman 2001, Cyr et al. 2007, Sala \& Lucchetti 2008, Fragoso \& Icely 2009, Padilla et al. 2011, Fitridge et al. 2012, Gubbins et al. 2012). However, most studies generically report biofouling problems, providing little evidence to elucidate or document the magnitude, spatial extent or duration of adverse effects. Biofouling studies that include $M$. galloprovincialis are no exception. Although this species is a successful and dominant invader in many temperate natural habitats globally (Apte et al. 2000, Bownes \& McQuaid 2006, Oyarzún et al. 2016), reports of significant biofouling impact in aquaculture are largely anecdotal (e.g. Fragoso \& Icely 2009, Watts et al. 2015).

The present study is unique in that access to an extensive industry dataset enabled a quantitative assessment of the impacts of $M$. galloprovincialis at a regional scale. This species has been an ongoing problem for mussel aquaculture in the Marlborough Sounds region since the industry began in the mid1970s, yet its impacts have never previously been comprehensively evaluated. Spatial patterns in the distribution of Mytilus revealed generally greatest abundances in the mid-Pelorus Sound area, where individual crops have on occasion experienced a Mytilus cover of $99 \%$; however, cover averaged across multiple crops outgrown within each farm was considerably less (see Fig. 2).

The reason for a greater prevalence of Mytilus in the mid-Pelorus sub-region is unknown, but may be related to larval recruitment. Analysis of spat monitoring data indicates that the same general area of central Pelorus Sound experiences a greater abundance of blue mussel recruitment than other areas (Atalah et al. 2017). Hydrodynamic modelling investigations have revealed the potential for high retention of larvae in Pelorus Sound, with bays of the inner and mid-Pelorus having low water flows $\left(<0.1 \mathrm{~m} \mathrm{~s}^{-1}\right)$ compared with main channel areas $\left(0.2\right.$ to $\left.0.3 \mathrm{~m} \mathrm{~s}^{-1}\right)$, and relatively slow flushing times ranging from ca. 28 to 50 d (Gibbs et al. 1991, Knight 2012, Broekhuizen et 
al. 2015). Even though M. galloprovincialis has the capacity for long-distance dispersal because of a planktonic larval duration of ca. 1 mo (Apte et al. 2000, McQuaid \& Phillips 2000), it is more commonly observed to recruit within a few $\mathrm{km}$ of source populations (McQuaid \& Phillips 2000). High larval retention over these scales conceivably means that the reproduction of abundant Mytilus populations in intensively farmed bays in the mid-Pelorus area becomes a self-perpetuating problem. Other recent studies revealed the potential for aquaculture structures to amplify the local self-recruitment of problematic biofoulers (Bloecher et al. 2015). This hypothesis would be worthy of further investigation, as it raises the possibility of farm fallowing as a management strategy, especially as Mytilus populations on adjacent cobble shores are relatively sparse throughout much of the sheltered Marlborough Sounds (B. M. Forrest pers. obs.). As such, fallowing may greatly reduce the adult population and associated larval inoculation pressure, depending on the spatial scales of larval dispersal and recruitment.

\section{Perna crop yield and impact of Mytilus}

The full range of mechanisms by which Perna yield is reduced by Mytilus are not completely understood, but the primary causes appear to be the loss of product resulting from smothering by Mytilus oversettlement, and sloughing when crop lines are lifted from the water during inspection and harvest. As sloughing creates bare space on the longline, it would be relatively straightforward to assess the magnitude of this effect during routine monitoring. Crop sloughing resulting from the weight of excess biofouling has been described in other musselgrowing localities that experience significant oversettlement of the culture species by biofoulers; most notably in eastern Canada, where excessive biofouling by tunicates (especially Ciona intestinalis) has been an ongoing problem for $>10$ yr (Carver et al. 2003, Ramsay et al. 2008, Paetzold et al. 2012). In Prince Edward Island, one of the measures employed to reduced crop loss by sloughing is to 'double sock' individual dropper lines (Bakker et al. 2011).

The high variability in the duration of the crop grow-out cycle (see Fig. 3), together with variability in annual Perna yield in the absence of Mytilus (see Fig. 4), indicates that factors in addition to Mytilus biofouling are important in mussel aquaculture production. As part of our initial data exploration, we rejected potential explanatory variables such as Perna seeding density, seed size and time or location of seeding with respect to the 2 spat types, as they showed no relationship with the prevalence of $\mathrm{My}$ tilus or yield of Perna. The key factor that we considered was the effect of spat type, with the reduced Perna yield from crops outgrown from Kaitaia compared with TOS spat being of particular interest. It is recognised by the industry that crops outgrown from Kaitaia spat may not reach harvest condition as quickly as TOS spat (Fox 2003), although the reasons are poorly understood. One possible explanation arises from recent experimental investigations, which suggest that mussels derived from Kaitaia stock show reduced feeding efficiency compared to TOS-derived mussels (N. Ragg, Cawthron Institute pers. comm.). Despite issues with Kaitaia spat, this source is critical for the industry to address seasonal constraints on the availability of TOS spat and the supply of mussels in suitable condition for harvest (Camara \& Symonds 2014).

The slower grow-out period for Kaitaia spat means crop lines will have a longer period of exposure to Mytilus, which was reflected in their greater mean and worst-case Mytilus cover compared with TOS crops (e.g. Table 1). A slower grow-out duration also means that crops are exposed to negative effects from a range of biofouling species in addition to Mytilus. Important biofoulers for the Marlborough Sounds industry are various tunicates (C. intestinalis, Didemnum vexillum, Diplosoma listerianum), macroalgae (Undaria pinnatifida, Colpomenia peregrina, Cladophora ruchingeri) and 'hard' biofouling species comprising various barnacles and serpulid tubeworms (Woods et al. 2012, Forrest et al. 2014, Pochon et al. 2015, Watts et al. 2015).

In addition to biofouling, aging Perna crops may be subject to increasing natural or predation-related mortality (e.g. from flatworms; Webb 2007), and there may be increased Perna sloughing due to weakened byssal attachment to lines. These and other possible factors lead to the counter-intuitive decrease in crop yield with increased grow-out duration evident in Fig. 3. This phenomenon was a consistent trend for each of the 4 production years represented by our data (results not shown). These patterns also reflect what the industry has observed over the long-term; i.e. as the grow-out period increases Perna may individually increase in size, but yields decrease over time because of loss from the crop lines.

Spatio-temporal variation in yield can also be expected due to variation in food availability (i.e. phytoplankton and other seston) to cultured Perna. In 
Pelorus Sound, temporal changes in Perna yield have been linked to changes in seston availability determined by oceanic upwelling at the entrance to the Sound and riverine nutrient inputs at the head (Zeldis et al. 2008, 2013). Depending on location, farm-scale seston depletion may also occur (Keeley et al. 2009, Stenton-Dozey 2013), with the extent depending on factors relating to environmental drivers, bay-scale farming intensity and farm-scale management (e.g. stocking density, crop rotation methods). The influence of Mytilus and other filterfeeding biofoulers on local-scale seston depletion processes (i.e. food competition with Perna) is unknown, but may also be important (Woods et al. 2012).

While a wide range of factors may affect Perna production; as Mytilus becomes abundant and dominates longline space, this species alone becomes an increasingly important driver of the impact on Perna yield. In this respect, it may seem counter-intuitive that Perna yield is not predicted to be zero at $100 \%$ Mytilus cover. This can be explained by a sampling artefact whereby the visual estimate of Mytilus is based on the primary substratum cover. Even though Mytilus biofouling may be visually dominant, Perna may still exist beneath the primary layer. An improvement to the assessment method could be achieved by applying quantitative methods; for example, more rigorously assessing the wet weight and/or size of Perna, Mytilus and other biofouling. Such an approach would slow production monitoring and may not at face value be considered by the industry to be feasible. However, the potential insights from more comprehensive data collection may lead to better informed management decisions and longer term production benefits.

\section{Economic consequences of Mytilus and comparison with international studies}

The estimated annual loss of ca. USD \$16.4 million attributed to Mytilus can be considered conservative on the basis that status quo regional revenue already incorporates existing Mytilus impacts. In the absence of Mytilus, regional revenue would be greater, with a proportionally greater decrease in annual Perna yield (hence economic loss) at a given level of $\mathrm{My}$ tilus biofouling. Nonetheless, it is highly significant that even a conservative estimate represents $10 \%$ of regional revenue from mussel aquaculture, especially given the national importance of the mussel industry. Mussel production in Marlborough is ca.
$60 \%$ of the national total, which itself accounts for ca. $75 \%$ of revenue of total aquaculture production (i.e. from all farmed species) in New Zealand (NZIER 2015). The fact that the impact of crop loss alone is estimated to exceed USD \$11 million ( $7 \%$ of regional revenue) indicates that management measures focusing on the crop grow-out cycle are particularly important. For example, we are aware of mussel farming companies that achieve greater yields than reported here by implementing comprehensive strategies to mitigate Mytilus impacts, and also carefully managing line and farm stocking densities to maintain an adequate food supply to Perna. For Mytilus, key crop management approaches used by the industry include removal by size-grading at the time of crop line seeding, and submerging crop lines during part of the grow-out period to avoid highest densities of Mytilus recruitment in surface waters (Atalah et al. 2017). Clearly, the costs and benefits of management, and the importance of different approaches will be situation-specific. Management decisions will need to consider the prevalence, depth-distribution and persistence of Mytilus at each farm location, the spat type used for grow-out and the importance of other factors that impact on yield such as described above.

The effects of Mytilus in the present study parallel some of the more significant examples from global studies that have estimated economic losses from biofouling in aquaculture. For example, for the European industry, Lane \& Willemsen (2004, p. 35) reported that 'biofouling on fish cages and shellfish sites costs the European industry between 5 and $10 \%$ of the industry value'. The same study noted that in some shellfish sectors, manual cleaning can cost up to $20 \%$ of product market value. A survey of 510 shellfish growers in the United States reported that biofouling accounted for an average of $14.7 \%$ of total annual operating costs, ranging from ca. 5 to $20 \%$ of costs across different growing regions (Adams et al. 2011). These figures appear to reflect the costs of biofouling management (of which labour was particularly important) as well as losses due to mortality and reduced marketability. The total cost of biofouling was estimated at USD \$21.6 million for US shellfish growers, representing around 10 to $11 \%$ of the approximate sector value of USD \$203 million reported by the authors. Although the Adams et al. (2011) study reflects a range of different species and production systems, the magnitude of impacts is similar to that reported for Mytilus in the present study.

In addition to these broad assessments, examples exist that reveal significant location-specific impacts 
and costs from biofouling by particular species. For example, the tunicate $C$. intestinalis is reported to lead to cultured mussel losses of ca. 50\% in Prince Edward Island under heavy biofouling of ca. $2 \mathrm{~kg}$ Ciona $\mathrm{m}^{-1}$ (Daigle \& Herbinger 2009). The boring sponge Cliona celata was reported to decrease the number of marketable oysters in Canada by 25 to $30 \%$ (Carver et al. 2010). In Europe, biofouling by tubeworms Pomatoceros triqueter has been reported to downgrade the value of cultured mussels by $56 \%$ (from $€ 1300$ to $€ 570$ tonne $^{-1}$ ), with local periodic heavy biofouling reducing marketable product by 60 to $90 \%$ (Lane \& Willemsen 2004). Finally, an outbreak of fanworms Hydroides elegans in Japan's Hiroshima Bay was reported to affect 6000 oyster rafts and led to a $60 \%$ drop in production in 1969 (Arakawa 1980). In our study, Mytilus impacts can clearly be far more significant at specific locations than reflected by the regional average (see Fig. 1). Hence, there are clearly site-specific considerations regarding the effort that is put into management and the economic viability of farming at a given location.

Although it is clear from the various studies cited above that the economic consequences of biofouling can be highly significant in shellfish aquaculture, it is difficult to compare studies to obtain a sense of the 'typical' magnitude of effects. The fact that many studies are based on anecdotal information and are vague with respect to the severity and scale (temporal and geographic) of adverse effects is one of the greatest challenges to understanding impacts. However, even where quantitative estimates have been made, different methods of reporting can thwart meaningful comparison. For example, few studies report on different culture species separately, and many do not differentiate between (or are vague with respect to) direct production impacts (e.g. on farmed stock) versus the costs of management. As in Table 2 of the present study, these aspects need to be clearly distinguished so that the benefits and costs of control measures (in terms of mitigating direct impacts) can be more clearly determined.

It is also evident that impacts are often expressed in different ways; for example, as a proportion of value or a proportion of production costs. Our experience is that the former tends to be publically available, whereas information on production costs is usually commercially sensitive. There is clearly a need not only for further quantitative studies of biofouling impact in aquaculture globally, but also for a more consistent approach to information reporting that addresses some of the limiting factors outlined above. This would better enable comparisons among differ- ent locations, biofouling species and types of aquaculture. Such improvements would provide a clearer appreciation of the impacts of biofouling, thereby giving the industry a more robust foundation for operational planning and management.

Acknowledgements. We are grateful to Sanford Ltd. and the New Zealand Marine Farming Associating for facilitating access to industry data, providing detail on sources of cost to mitigate Mytilus impacts, and for providing background information and helpful feedback on this study. This research was funded by the New Zealand Ministry of Business, Innovation and Employment under Contract CAWX1315 (The Cultured Shellfish Programme: Enabling, Growing, and Securing NZ's Shellfish Aquaculture Sector).

\section{LITERATURE CITED}

Adams CM, Shumway SE, Whitlatch RB, Getchis T (2011) Biofouling in marine molluscan shellfish aquaculture: a survey assessing the business and economic implications of mitigation. J World Aquacult Soc 42:242-252

Alagarswami K, Chellam A (1976) On fouling and boring organisms and mortality of pearl oysters in the farm at Veppalodai, Gulf of Mannar. Indian J Fish 23:10-22

Apte S, Holland BS, Godwin LS, Gardner JPA (2000) Jumping ship: a stepping stone event mediating transfer of non-indigenous species via a potentially unsuitable environment. Biol Invasions 2:75-79

Arakawa KY (1980) Prevention and removal of fouling on cultured oysters: a handbook for growers. Maine Sea Grant Technical Report 56. http://nsgd.gso.uri.edu/meu/ meut80002.pdf (accessed 22 December 2015)

Atalah J, Rabel H, Forrest BM (2016) Blue mussel oversettlement predictive model and web application. Cawthron Report No. 2801, Cawthron Institute, Nelson

* Atalah J, Rabel H, Forrest BM (2017) Modelling long-term recruitment patterns of blue mussels Mytilus galloprovincialis: a biofouling pest of green-lipped mussel aquaculture in New Zealand. Aquacult Environ Interact 9: 103-114

Bakker JA, Paetzold SCP, Quijón A, Davidson J (2011) The use of food grade oil in the prevention of vase tunicate fouling on mussel aquaculture gear. Manage Biol Invasions 2:15-25

* Bloecher N, Floerl O, Sunde LM (2015) Amplified recruitment pressure of biofouling organisms in commercial salmon farms: potential causes and implications for farm management. Biofouling 31:163-172

Booth SR (2014) Dichotomous key and illustrated guide to the pests of bivalve aquaculture in Washington and Oregon. Pacific Shellfish Institute, Olympia, WA

Bownes SJ, McQuaid CD (2006) Will the invasive mussel Mytilus galloprovincialis Lamarck replace the indigenous Perna perna L. on the south coast of South Africa? J Exp Mar Biol Ecol 338:140-151

Broekhuizen N, Hadfield M, Plew D (2015) A biophysical model for the Marlborough Sounds, Part 2: Pelorus Sound. NIWA Client Report No. CHC2014-130, National Institute of Water and Atmospheric Research, Christchurch

Camara MD, Symonds JE (2014) Genetic improvement of New Zealand aquaculture species: programmes, pro- 
gress and prospects. NZ J Mar Freshw Res 48:466-491

Carver CE, Chisholm A, Mallet al. (2003) Strategies to mitigate the impact of Ciona intestinalis (L.) biofouling on shellfish production. J Shellfish Res 22:621-631

Carver CE, Thériault I, Mallet al. (2010) Infection of cultured eastern oysters Crassostrea virginica by the boring sponge Cliona celata, with emphasis on sponge life history and mitigation strategies. J Shellfish Res 29:905-915

* Claereboudt MR, Bureau D, Côté J, Himmelman JH (1994) Fouling development and its effect on the growth of juvenile giant scallops (Placopecten magellanicus) in suspended culture. Aquaculture 121:327-342

* Cyr C, Myrand B, Cliche G, Desrosiers G (2007) Weekly spat collection of sea scallop, Placopecten magellanicus, and undesirable species as a potential tool to predict an optimal deployment period of collectors. J Shellfish Res 26: 1045-1054

Daigle RM, Herbinger CM (2009) Ecological interactions between the vase tunicate (Ciona intestinalis) and the farmed blue mussel (Mytilus edulis) in Nova Scotia, Canada. Aquat Invasions 4:177-187

de Francesco J, Murray K (2010) Pest management strategic plan for bivalves in Oregon and Washington. In: Clarke D (ed) Summary of workshop held March 11, 2010, Long Beach, WA. Western Integrated Pest Management Center, Davis, CA

* de Sá FS, Nalesso RC, Paresque K (2007) Fouling organisms on Perna perna mussels: Is it worth removing them? Braz J Oceanogr 55:155-161

Dharmaraj S, Chellam A, Velayudhan TS (1987) Biofouling, boring and predation of pearl oyster. In: Alagarswami K (ed) Pearl culture, chapter 14. CMFRI Bulletin 39. Central Marine Fisheries Research Institute, Cochin, p 92-97

Elston R (1997) Pathways and management of marine nonindigenous species in the shared waters of British Columbia and Washington: final report January 1997, prepared for the Puget Sound Water Quality Authority, US Environmental Protection Agency Region 10, and Department of Fisheries and Oceans, Canada. AquaTechnics, Carlsborg, WA

Fitridge I, Dempster T, Guenther J, de Nys R (2012) The impact and control of biofouling in marine aquaculture: a review. Biofouling 28:649-669

Fletcher LM, Forrest BM, Bell JJ (2013) Impacts of the invasive ascidian Didemnum vexillum on green-lipped mussel Perna canaliculus aquaculture in New Zealand. Aquacult Environ Interact 4:17-30

Forrest B, Cahill P, Newcombe E, Taylor D (2014) Marine pests and management priorities for shellfish aquaculture. Cawthron Report No. 2285, Cawthron Institute, Nelson

Fox SP (2003) The growth of cultured Perna canaliculus in Pelorus Sound, New Zealand: the importance of spat origin, environment, and time of harvest. PhD thesis, University of Canterbury, Christchurch

Fragoso B, Icely JD (2009) Upwelling events and recruitment patterns of the major fouling species on coastal aquaculture (Sagres, Portugal). J Coast Res SI56:419-423

Gardner JPA, Zbawicka M, Westfall KM, Wenne R (2016) Invasive blue mussels threaten regional scale genetic diversity in mainland and remote offshore locations: the need for baseline data and enhanced protection in the Southern Ocean. Glob Change Biol 22:3182-3195

Gibbs MM, James MR, Pickmere SE, Woods PH, Shakespeare BS, Hickman RW, Illingworth J (1991) Hydro- dynamic and water column properties at six stations associated with mussel farming in Pelorus sound, 1984-85. NZ J Mar Freshw Res 25:239-254

* Glasby TM, Connell SD (2001) Orientation and position of substrata have large effects on epibiotic assemblages. Mar Ecol Prog Ser 214:127-135

Gubbins M, Snow M, Hermann G, Dias J and others (2012) Mytilus trossulus: managing impact on sustainable mussel production in Scotland. Scottish Aquaculture Research Forum, (SARF) 064. www.sarf.org.uk/cmsassets/documents/48901-352547.sarf064.pdf (accessed 26 March 2014)

Hancock DA (1954) The destruction of oyster spat by Urosalpinx cinerea (Say) on Essex oyster beds. ICES J Mar Sci 20:186-196

Jeffs AG, Holland RC, Hooker SH, Hayden BJ (1999) Overview and bibliography of research on the greenshell mussel, Perna canaliculus, from New Zealand waters. J Shellfish Res 18:347-360

Jenkins RJ (2011) A review of the blue mussel (Mytilus galloprovincialis) in reference to the culture of Perna canaliculus in the Marlborough Sounds. Prepared for The Spat Committee, Marine Farming Association, Blenheim

Keeley N, Forrest B, Hopkins G, Gillespie P and others (2009) Review of the ecological effects of farming shellfish and other non-finfish species in New Zealand. Cawthron Report No. 1476, Cawthron Institute, Nelson

Khalaman VV (2001) Succession of fouling communities on an artificial substrate of a mussel culture in the White Sea. Russ J Mar Biol 27:345-352

Knight B (2012) Validation report for updated hydrodynamic models of the Marlborough Sounds. Cawthron Report No. 2185, Cawthron Institute, Nelson

Lacoste E, Gaertner-Mazouni N (2015) Biofouling impact on production and ecosystem functioning: a review for bivalve aquaculture. Rev Aquacult 7:187-196

Lane A, Willemsen P (2004) Collaborative effort looks into biofouling. Fish Farming Int, September 2004, IntraFish Media AS, Bergen, p 34-35

*McQuaid CD, Phillips TE (2000) Limited wind-driven dispersal of intertidal mussel larvae: in situ evidence from the plankton and the spread of the invasive species Mytilus galloprovincialis in South Africa. Mar Ecol Prog Ser 201:211-220

*Meese RJ, Tomich PA (1992) Dots on the rocks: a comparison of percent cover estimation methods. J Exp Mar Biol Ecol 165:59-73

NZIER (New Zealand Institute of Economic Research) (2015) The economic contribution of marine farming in the Marlborough region: a computable general equilibrium (CGE) analysis. New Zealand Institute of Economic Research, Wellington

O'Beirn FX, Ross PG, Luckenbach MW (2004) Organisms associated with oysters cultured in floating systems in Virginia, USA. J Shellfish Res 23:825-829

* Oyarzún PA, Toro JE, Cañete JI, Gardner JPA (2016) Bioinvasion threatens the genetic integrity of native diversity and a natural hybrid zone: smooth-shelled blue mussels (Mytilus spp.) in the Strait of Magellan. Biol J Linn Soc 117:574-585

Padilla DK, McCann MJ, Shumway SE (2011) Marine invaders and bivalve aquaculture: sources, impacts and consequences. In: Shumway SE (ed) Shellfish aquaculture and the environment. Wiley-Blackwell, Oxford, p 395-424 ₹Paetzold SC, Giberson DJ, Hill J, Davidson JDP, Davidson J 
(2012) Effect of colonial tunicate presence on Ciona intestinalis recruitment within a mussel farming environment. Manage Biol Invasions 3:15-23

Pinheiro J, Bates D DebRoy S, Sarkar D, R Core Team (2016) nlme: linear and nonlinear mixed effects models. R package version 3.1-124. http://CRAN.R-project.org/ package $=$ nlme

Pochon X, Atalah J, Wood SA, Hopkins GA, Watts A, Boedeker C (2015) Cladophora ruchingeri (C. Agardh) Kützing, 1845 (Cladophorales, Chlorophyta): a new biofouling pest of green-lipped mussel Perna canaliculus (Gmelin, 1791) farms in New Zealand. Aquat Invasions 10:123-133

R Core Team (2014) R: a language and environment for statistical computing. R Foundation for Statistical Computing, Vienna. www.R-project.org/

Ramsay A, Davidson J, Landry T, Arsenault G (2008) Process of invasiveness among exotic tunicates in Prince Edward Island, Canada. Biol Invasions 10:1311-1316

Rocha RM, Kremer LP, Baptista MS, Metri R (2009) Bivalve cultures provide habitat for exotic tunicates in southern Brazil. Aquat Invasions 4:195-205

Sala A, Lucchetti A (2008) Low-cost tool to reduce biofouling in oyster longline culture. Aquacult Eng 39:53-58

* Sievers M, Fitridge I, Dempster T, Keough MJ (2013) Biofouling leads to reduced shell growth and flesh weight in the cultured mussel Mytilus galloprovincialis. Biofouling 29:97-107

Stasinopoulos M, Rigby B (2014) Gamlss.mx: a GAMLSS add on package for fitting mixture distributions. $\mathrm{R}$ package version 4.2-7. http://CRAN.R-project.org/

Editorial responsibility: Peter Cranford,

Dartmouth, Nova Scotia, Canada package $=$ gamlss.mx

Stenton-Dozey J (2013) Literature review of ecological effects of aquaculture: pelagic effects. Ministry for Primary Industries, Wellington

Watts AM, Goldstien SJ, Hopkins GA (2015) Characterising biofouling communities on mussel farms along an environmental gradient: a step towards improved risk management. Aquacult Environ Interact 8:15-30

Webb S (2007) Pathogens and parasites of the mussel Mytilus galloprovincialis and Perna canaliculus: assessment of the threats faced by New Zealand aquaculture. Cawthron Report No. 1334, Cawthron Institute, Nelson

WWoods CC, Floerl O, Hayden BJ (2012) Biofouling on Greenshell ${ }^{\mathrm{TM}}$ mussel (Perna canaliculus) farms: a preliminary assessment and potential implications for sustainable aquaculture practices. Aquacult Int 20:537-557

Keldis JR, Howard-Williams C, Carter CM, Schiel DR (2008) ENSO and riverine control of nutrient loading, phytoplankton biomass and mussel aquaculture yield in Pelorus Sound, New Zealand. Mar Ecol Prog Ser 371: 131-142

K Zeldis JR, Hadfield MG, Booker DJ (2013) Influence of climate on Pelorus Sound mussel aquaculture yields: predictive models and underlying mechanisms. Aquacult Environ Interact 4:1-15

Zuur AF, Ieno EN (2016) A protocol for conducting and presenting results of regression-type analyses. Methods Ecol Evol 7:636-645

Kuur AF, Ieno EN, Elphick CS (2010) A protocol for data exploration to avoid common statistical problems. Methods Ecol Evol 1:3-14

Submitted: October 5, 2016; Accepted: January 20, 2017

Proofs received from author(s): March 2, 2017 